\title{
Article \\ A Novel Coaxial Balance Mechanism for Reciprocating Piston Engines
}

\author{
Nanxiang Guan, Ao Wang, Yongpeng Gu, Zhifeng Xie *iD and Ming Zhou \\ School of Aerospace Engineering, Tsinghua University, Beijing 100084, China; \\ guannx@mail.tsinghua.edu.cn (N.G.); wa20@mails.tsinghua.edu.cn (A.W.); guyp@mail.tsinghua.edu.cn (Y.G.); \\ zmzlh@mail.tsinghua.edu.cn (M.Z.) \\ * Correspondence: xzhf@mail.tsinghua.edu.cn
}

Citation: Guan, N.; Wang, A.; Gu, Y.; Xie, Z.; Zhou, M. A Novel Coaxial Balance Mechanism for Reciprocating Piston Engines. Appl. Sci. 2021, 11, 5647. https://doi.org/10.3390/ app11125647

Academic Editor: Ricardo Novella Rosa

Received: 2 May 2021

Accepted: 14 June 2021

Published: 18 June 2021

Publisher's Note: MDPI stays neutral with regard to jurisdictional claims in published maps and institutional affiliations.

Copyright: (c) 2021 by the authors. Licensee MDPI, Basel, Switzerland. This article is an open access article distributed under the terms and conditions of the Creative Commons Attribution (CC BY) license (https:/ / creativecommons.org/licenses/by/ $4.0 /)$.
Abstract: Vibration is an important issue faced by reciprocating piston engines, and is caused by reciprocating inertia forces of the piston set. To reduce the vibration without changing the main structure and size of the original engine, we proposed a novel coaxial balance mechanism design based on a compact unit body. By introducing a second-order balance mass, this mechanism can significantly increase the efficiency of vibration reduction. The proposed mechanism can effectively balance the first-order and second-order inertia forces with the potential of balancing high-order inertia forces. To accurately determine the second-order balance mass, a closed-form method was developed. Simulation results with a single-cylinder piston DK32 engine demonstrate the effectiveness and advantage of the proposed mechanism. At a crankshaft speed of $2350 \mathrm{r} / \mathrm{min}$, compared with the first-order balance device, the average root mean square velocity of the test points on the engine's cylinder was reduced by $97.31 \%$, and the support reaction force was reduced by $96.54 \%$.

Keywords: piston engine; vibration reduction; coaxial balance mechanism; compact unit body; closed-form

\section{Introduction}

Vibration is one of the most commonly observed phenomena in reciprocating piston engines, and particularly this with a single cylinder. Excessive vibration leads to fatigue damage of engine parts, and affects the stability and mechanical efficiency of the engine's operation. The resulting noise may also cause irreversible hearing loss in operators $[1,2]$. Numerous scholars have carried out in-depth research on vibration sources. For an engine system, the vibration is determined by the excitation force and the inherent characteristics of the system structure. The excitation force mainly includes the gas explosion pressure and inertial load, whereas the inherent characteristics depend on the inertia and rigidity of the engine body structure and mounting base. Carlucci et al. [3] studied the relationship between injection parameters (e.g., injection pressure, injected quantities, and injection timing) and engine block vibration. Griffiths et al. [4] investigated the effect of coolant temperature on the vibration of a single-cylinder diesel engine by frequency spectrum analysis and noted that piston slap was also the main factor that affected the vibration. Fabi et al. [5] further studied the influence of piston slap on engine block vibration. Wang et al. [6] explored the relationship between faults in the valve train and the vibration of a diesel cylinder head, and a fault analysis method of vibration signals using Wigner-Ville distributions and probabilistic neural networks was developed. Singh et al. [7-9] studied the effects of engine support and installation methods on engine vibration. Li et al. [10] analyzed the inertia force produced by piston motion in a reciprocating piston engine. This kind of inertia force makes the engine body generate both noise and vibration. To improve the balance of the engine, they designed a balance mechanism to eliminate the influence of inertia force. Aversa et al. [11] studied the influence of engine static and dynamic balance on the vibration of the engine. Razzini J. et al. [12] calculated the dynamic responses of 
two support cushions of the engine, which was excited by the inertial forces related to the reciprocating movement of the pistons and connecting rods, and unbalanced crankshaft counterweights. Hojat et al. [13] reviewed recent research that was focused on reducing and isolating engine vibration, including the effect of unbalanced reciprocating and rotating parts. The above research showed that the gas pressure curve could be adjusted via the engine electronic control system to reduce vibration; however, reducing the inertial load of the engine must be achieved by designing a balance mechanism. Therefore, optimizing the balance mechanism for engines in which the main configuration had been determined was an economical and effective vibration reduction measure.

In 1907, Dr. Frederick W. Lanchester invented a forward and reverse double balance shaft mechanism for the reciprocating inertial force of the engine. The centrifugal force generated by the mechanism could offset the unbalanced inertial force component for part of the engine [14]. Since 1970, many researchers have continuously improved the above-mentioned traditional balancing mechanism. For example, the height of the two shafts was varied in one mechanism. Because the two shafts are not symmetrical, with respect to the center of the crankshaft, a moment will be generated, offsetting a part of the second moment of inertia based on balancing the secondary reciprocating inertia force [15]. Oguchi Koji et al. designed a silent crankshaft in the engine to reduce its second-order vibration and improve the NVH performance in cars [16]. St. Huege et al. developed an in-line four-cylinder engine with a double balance shaft device, which greatly improved the NVH performance [17]. Shoji Adachi et al. optimized the mass of reciprocating motion and valve train motion, greatly reducing the second-order inertial force [18]. Zhang carried out systematic research and software development on the balance schemes of in-line and V-type engines [19].

There are two defects with the existing balancing mechanism. The first is that the structure is not compact enough. The balance mechanism with corresponding auxiliary parts increases the volume and mass of the engine. Generally, one balancing mechanism can only balance the inertial load of the corresponding order. Thus, the current balancing mechanism is not suitable for a compact engine. In general, for a single-cylinder piston engine, only the first-order balance mechanism is installed due to cost, and the secondand higher-order inertia forces are ignored. As a result, the balance effect is not satisfied, leading to significant engine vibration and loud noise. The second-order inertia force has a significant influence on engine vibration. Taking the DK32 single-cylinder engine [20,21] developed by the author's laboratory as an example, the maximum value of second-order inertia force could reach $4900 \mathrm{~N}$ at the rated speed of $2350 \mathrm{r} / \mathrm{min}$, which is unacceptable for an engine with high vibration performance.

The second defect with the existing balancing mechanism is an error in calculating the inertial load. Conventional methods [22,23] employ Taylor expansion of the inertial load function with respect to $\lambda$ (crank-conrod ratio) and then expand the coefficients of the previous orders into Fourier series with respect to the $\alpha$ crank angle. Finally, the coefficient of each order in the Fourier series obtained by integration can represent the characteristics of the inertia load. However, we found that the high-order term coefficient of Taylor expansion significantly impacts lower-order terms of the Fourier series, meaning the calculation of second- and higher-order inertia load by conventional methods is not accurate.

In this study, we focused on achieving vibration reduction of a single-cylinder engine by reducing the inertia force, aiming to design a mechanism that can eliminate the effect of inertia force as much as possible. Additionally, considering the cost constraints of the engine, the balance mechanism should increase the number and volume of engine parts as little as possible. Firstly, we adopt a novel closed-form method [24] to accurately calculate inertia load, which considers all the orders of $\lambda$, and only carries out Fourier expansion of the inertia load function. Compared with the conventional methods, the novel closedform method can accurately calculate the inertia load. Secondly, we designed a balance mechanism to balance many-order inertia forces once to improve space utilization. 
A set of novel coaxial balance mechanisms [25] that can automatically balance firstand second-order inertia forces was designed in this study by comprehensively considering the manufacturing cost, size limitation, and engine vibration reduction. The principle of the novel mechanism was analyzed and studied in detail. The novel mechanism adopted the idea of a unit-body module without increasing the size of the balance mechanism or changing the main structure and size of the original engine. This could be realized by modifications inside the original first-order balance mechanism in a highly compact form. Additionally, the novel closed-form method was used to accurately calculate the second-order inertia force, and an accurate balance mass was then designed so that the balance mechanism can completely balance the second-order inertia force. Hence, this balance mechanism was able to reduce vibration to a greater extent.

In terms of the engine vibration simulation method, research shows that the use of a flexible body model has a greater impact on the simulation accuracy of the whole engine [26-30]. Because piston engines involve multiple components, it is generally necessary to establish a multi-body dynamic model of the whole engine.

This paper is organized as follows. Section 2 introduces the design scheme of the novel first- and second-order coaxial balance mechanism in detail; Section 3 presents the application of novel first- and second-order coaxial balance mechanisms in the DK32 engine; and Section 4 reports on the dynamics simulation for the DK32 engine using the novel coaxial balance mechanism to verify its excellent vibration reduction performance.

\section{Design of a Novel Coaxial Balance Mechanism}

This section discusses the design of piston engine inertia force by analyzing the characteristics of the coaxial balance mechanism and combining this with mechanical design.

\subsection{Closed-Form Method for the Calculation of Inertia Forces}

A schematic of a single-cylinder piston engine crankshaft-connecting rod mechanism is shown in Figure 1. Herein, $m$ is the reciprocating mass of the piston crankshaft-connecting rod mechanism, $R$ is the crankshaft radius, $L$ is the length of the connecting rod, and $\lambda$ is the ratio of crankshaft radius to connecting rod length (i.e., $\lambda=R / L$, generally taking the value of 1/3). Further, $\alpha=\omega t$ is the crank angle and $\omega$ is the angular velocity of crankshaft rotation.

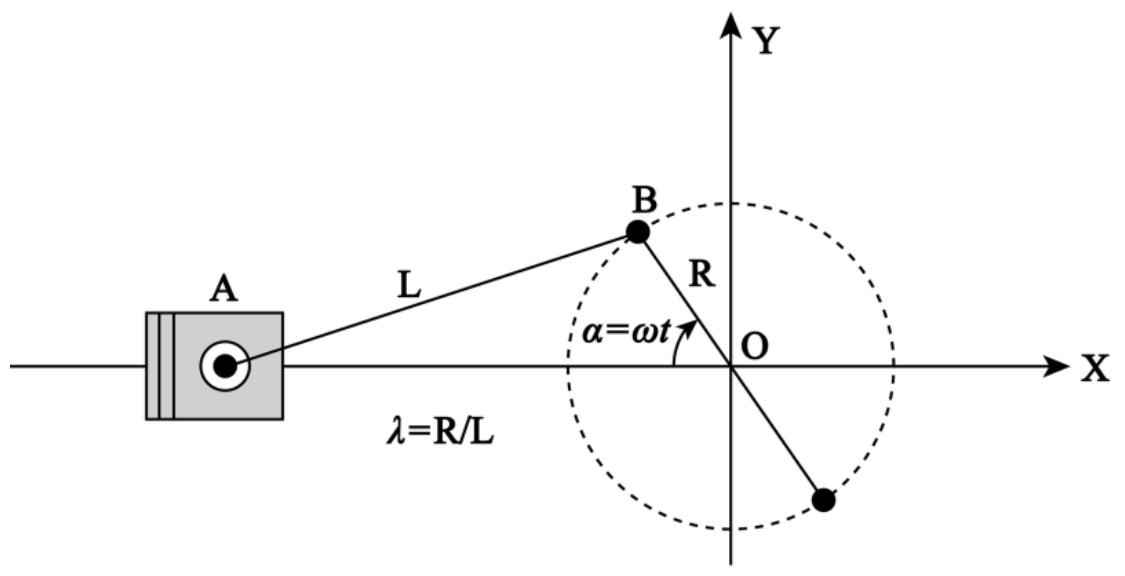

Figure 1. Schematic of a single-cylinder piston engine crankshaft-connecting rod mechanism.

Based on the kinematic analysis of the crankshaft-connecting rod mechanism, the composition of the inertia force produced by the reciprocating motion of the single-cylinder engine piston obtained by the traditional method [23] is expressed as follows:

$$
F_{T M}=b_{1-T M} \cos \alpha+b_{2-T M} \cos 2 \alpha+\sum_{n=2}^{\infty} b_{2 n-T M} \cos 2 n \alpha
$$

where $b_{1-T M}=m \omega^{2} R, b_{2-T M}=m \omega^{2} R \lambda$. 
Using the novel closed-form method [24], the composition of single-cylinder engine inertia force can be obtained as:

$$
F_{C F}=b_{1-C F} \cos \alpha+b_{2-C F} \cos 2 \alpha+\sum_{n=2}^{\infty} b_{2 n-C F} \cos 2 n \alpha
$$

where $b_{1-C F}=m \omega^{2} R$ and $b_{2-C F}=16 m \omega^{2} L\left[\left(2-\lambda^{2}\right)\right.$ EllipticE $\left(\lambda^{2}\right)-2\left(1-\lambda^{2}\right)$ EllipticK $\left.\left(\lambda^{2}\right)\right] / 3 \pi \lambda^{2}$; EllipticE and EllipticK are the complete elliptic integrals of the first and second kind, respectively.

In Equation (2), the inertial force can be divided into first-order inertial force, second-order inertial force, fourth-order inertial force, etc., by multiples of the angular velocity of the engine rotation; that is, $\omega, 2 \omega, 4 \omega \ldots$ For commercial piston single-cylinder engines, its balance mechanism generally only balances the first-order inertia force. In multi-cylinder engines, the first-order inertia force can be self-balanced by designing the spatial configuration of the crankshaft, and the second-order inertia force needs to be balanced by setting a second-order balance mechanism.

It can be observed that the first-order inertia force obtained by the two methods is the same. Therefore, if only the first-order inertia force of the single-cylinder engine is considered to be balanced, either method can be used. However, although the first-order inertia force can be balanced using these methods, the remaining second-order and higherorder inertia force is still not negligible, which is the main cause of engine vibration. A more accurate expression of second-order inertia force is beneficial to eliminate the effect of the second-order inertia force. In fact, from the comparative analysis in [24], we know that when the $\lambda$ variation range is $0.25-0.4$, the calculation accuracy of second-order inertia force can be improved by $1.5-4 \%$ by adopting a novel closed-form method. Hence, using a novel closed-form method to calculate second-order inertia force is an important means of reducing single-cylinder engine vibration. This method can also be adapted to improve the high-order balance performance of the multiple-cylinder engine because it still provides accurate results if the effect of fourth-order inertia force is further considered.

\subsection{Design Principles and Ideas of a Novel Coaxial Balance Mechanism}

To balance the second-order inertia force, it is necessary to design a rotating balance mass that rotates at twice the crankshaft speed, which naturally requires corresponding gear drive and lubrication mechanisms. Thus, it is necessary to design a new larger engine body for the traditional mechanism. Because the additional parts increase the cost and size of the engine, engine manufacturers are commonly unwilling to make large changes to the engine body.

The design scheme of a coaxial mechanism of first-order and second-order balance shafts is proposed in this study to solve the above issues, as shown in Figure 2. The planetary gear transmission mechanism was used for transmission, and the appropriate speed ratio of internal and external gears could be achieved by adjusting the ratio of the number of teeth of the inner gear ring and sun gear.

This study also proposes a design concept that uses a compact unit body, i.e., the second-order balance mass block is arranged inside the original first-order balance mass block, and the two balance mass blocks perform coaxial rotation, which saves significant space. After adding a second-order balance mechanism, the original configuration and size of the balance mechanism were not changed.

Based on the above mechanical design principles and the idea of a compact unit body, a novel coaxial second-order balance mechanism was designed in this study, as shown in Figure 3. The novel coaxial balance mechanism is a unit-body module, including shell, first-order balance shafts, second-order balance shafts, and planetary gear transmission mechanisms. The second-order balance shafts are installed in the shaft hole of the firstorder balance shafts; their rotational axes coincide. The external gear with internal teeth (i.e., the internal gear in the planetary gear mechanism) is fixed at one end of the first-order balance shaft. The internal gear with the external teeth (the sun gear in the planetary gear mechanism) is fixed at one end of the second-order balance shafts, and the middle gear 
(the planetary gear in the planetary gear mechanism) meshes with the internal gear and the external gear, respectively, thereby transmitting the rotation of the first-order balance shaft to the second-order balance shaft through the planetary gear mechanism.

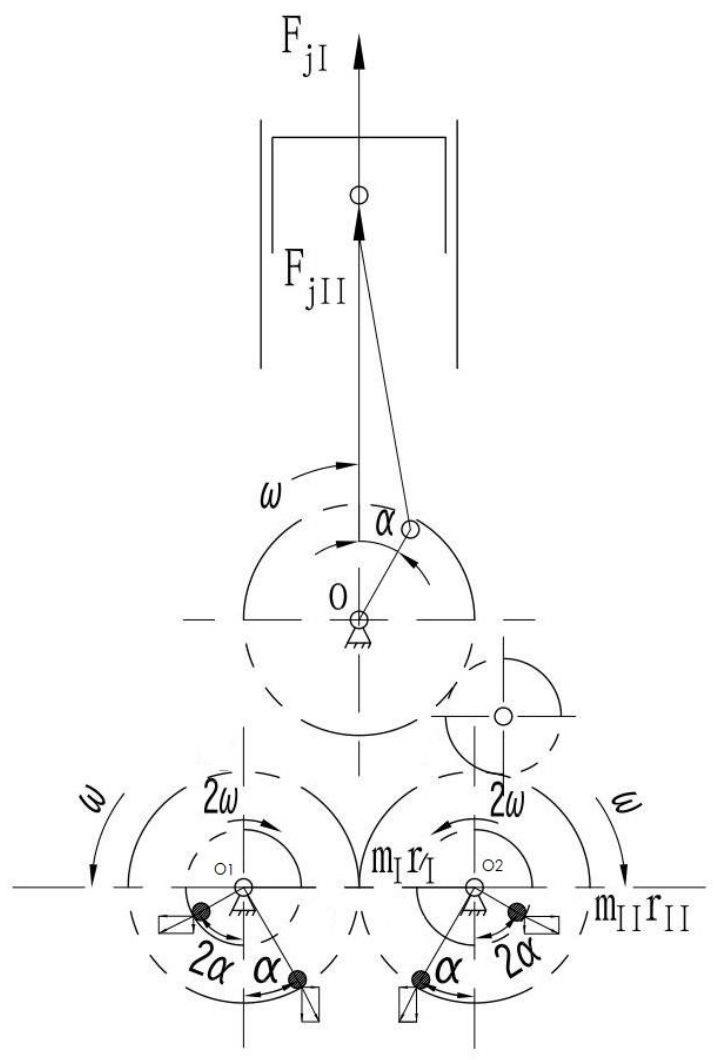

Figure 2. Schematic of single-cylinder engine coaxial balance mechanism.

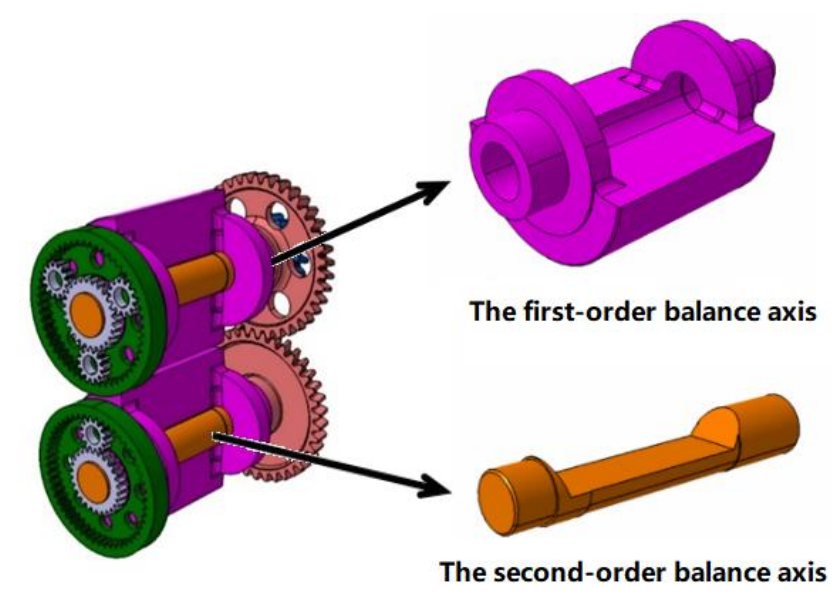

Figure 3. A 3D diagram of the coaxial balance mechanism.

Additionally, the second-order balance shafts operate at twice the speed of the first-order balance shaft based on the design of a suitable ratio of internal and external gears based on mechanical design principles. When the engine is in operation, the crankshaft drives the first-order balance shaft to rotate through the gear transmission, and the speed remains the same; when the first-order balance shaft drives the second-order balance shaft to rotate through the middle gear, the speed doubles. The balance mechanism can balance the first- and second-order inertia forces of the engine crankshaft-connecting rod mechanism.

To counteract the inertia force along the direction of piston motion and avoid generating additional inertia force perpendicular to the direction of piston motion, the balance 
shaft is generally designed with a semi-cylindrical balance mass biaxial counter-rotation, as shown in Figure 3.

In multi-cylinder engines, such as an in-line four-cylinder engine, the first-order inertia force is inherently balanced, and the proposed design solution can expand this application. An external balance shaft can be used to balance the second-order inertia force, and an internal balance shaft can be used to balance the fourth-order inertia force. Therefore, the coaxial balance mechanism design scheme has the potential to balance high-order inertia force.

\subsection{Application Cases}

The novel coaxial balance mechanism was applied to the DK32 single-cylinder diesel engine developed in the laboratory [20,21].

A simplified balance shaft mechanism is shown in Figure 4. The light blue semicircle in the picture represents the counter-rotating mass, in which $M_{i}$ is the mass of balance weight of a single balance shaft, and $\omega_{i}$ is the rotational angular velocity of balance shaft. The rotational angular velocity of the first-order balance shaft is the same as that of the crankshaft. The rotational angular velocity of the second-order balance shaft is twice that of the crankshaft; that is, $\omega_{1}=\omega$ and $\omega_{2}=2 \omega . \alpha_{i}=\omega_{i} t, r$, denotes the distance from the center of mass of balance weight to the axle center, and $F_{i 1}$ and $F_{i 2}$ denote the resultant forces of the two balance weight inertia forces. When the balance shaft rotates, the resultant inertia force of each balance weight acts on the center of mass, and the action line of the force passes through the balance shaft axle center, which has a size of:

$$
\left|F_{i 1}\right|=\left|F_{i 2}\right|=M_{i} \omega_{i}^{2} r
$$

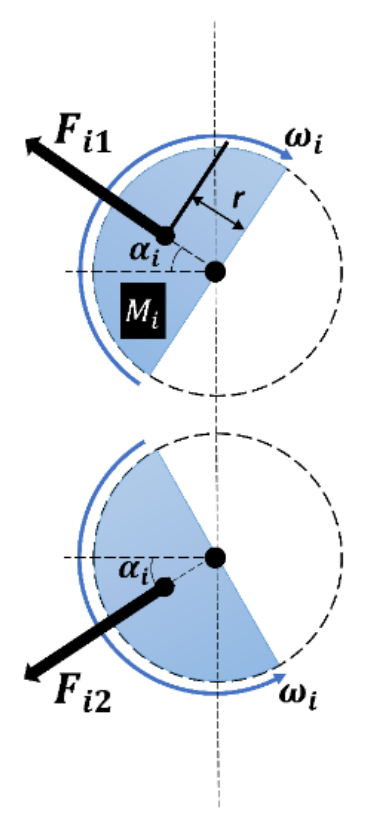

Figure 4. Simplified diagram of counter-rotating balance shafts.

Because the speed of the two balance shafts is the same and the crank angle is also the same, the components of $F_{i 1}$ and $F_{i 2}$ perpendicular to the direction of piston motion are offset. Then, the resultant balance force of the components in the direction of piston motion can be expressed as:

$$
F_{b i}=2 M_{i} \omega_{i}^{2} r \cos \alpha_{i}
$$

where $F_{b i}$ is balanced with the inertia force generated by the piston.

For the first-order balance shaft:

$$
2 M_{1} \omega^{2} r=m \omega^{2} R
$$


Therefore, the balance weight mass $M_{1}$ of the first-order balance shaft is:

$$
M_{1}=\frac{m R}{2 r}
$$

Considering the second-order balance shaft:

$$
8 M_{2} \omega^{2} r=\frac{16 m \omega^{2} L\left[\left(2-\lambda^{2}\right) \text { EllipticE }\left(\lambda^{2}\right)-2\left(1-\lambda^{2}\right) \operatorname{EllipticK}\left(\lambda^{2}\right)\right]}{3 \pi \lambda^{2}}
$$

The balance weight mass $M_{2}$ of the second-order balance shaft is:

$$
M_{2}=\frac{2 m L\left[\left(2-\lambda^{2}\right) \operatorname{EllipticE}\left(\lambda^{2}\right)-2\left(1-\lambda^{2}\right) \operatorname{EllipticK}\left(\lambda^{2}\right)\right]}{3 \pi r \lambda^{2}}
$$

The required balance weight mass was thus designed, and the size of the balance shaft was then able to be determined to counteract the first- and second-order inertia forces produced by the reciprocating motion of the piston set and the small end of the connecting rod.

In the proposed balance mechanism, both first- and second-order balance shafts were installed in the shell, and only a rotating input gear was needed to connect to the crankshaft. The unit-body design could be used to arrange the parts and components of the engine more flexibly without increasing the size of the engine. In addition, the structure improved the assembly form of a conventional engine and adopted an integral installation mode, which is quick and straightforward to install and disassemble. This structure could be widely used in various types of piston engines to reduce the vibration and noise of the engine and improve its service life. The layout of the compact coaxial balance mechanism installed on the single-cylinder engine is shown in Figure 5.

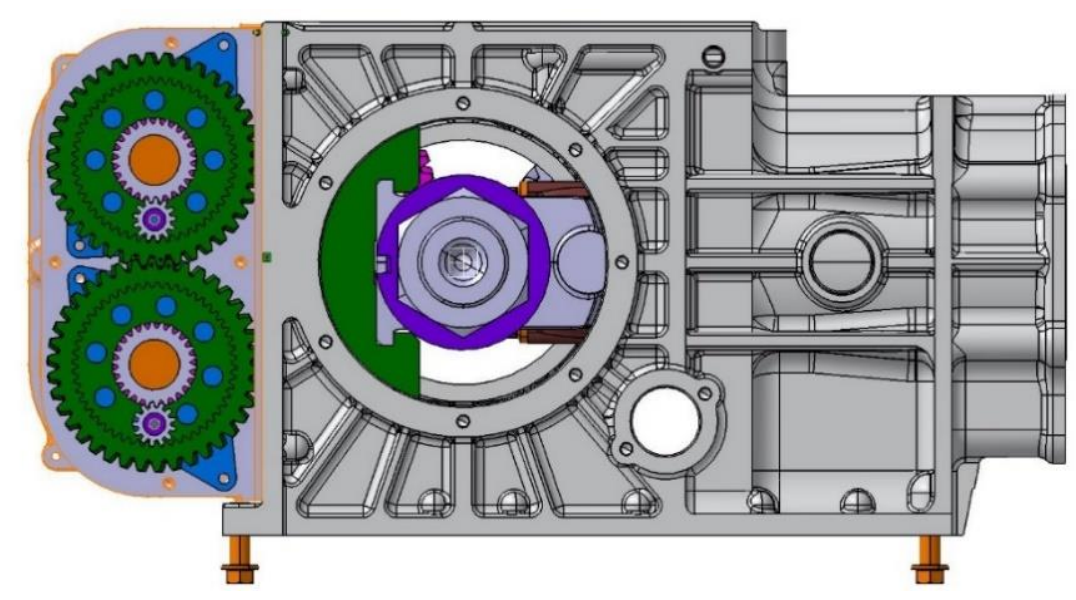

Figure 5. The layout of compact coaxial balance mechanism on a single-cylinder engine.

\section{Dynamics Simulations}

In this section, Adams, a commercial software program used for dynamic analysis, was applied to the dynamic analysis of a DK32 single-cylinder engine in which a balance mechanism was installed. The vibration reduction effect of this coaxial second-order balance mechanism was then verified by numerical simulation.

The complete engine model was established in the MSC Adams software (MSC Corp., Irvine, CA, USA), version 2020, as shown in Figure 6. The engine body, crankshaft, and the support structure supporting the single-cylinder engine were modeled as flexible bodies. The component modal parameters of the DK32 engine are shown in Tables 1 and 2. The engine was connected with the plate via two flexible supports, the front support was near the cylinder head, the rear support was near the balance mechanism, and the plate was fixed to the ground. 


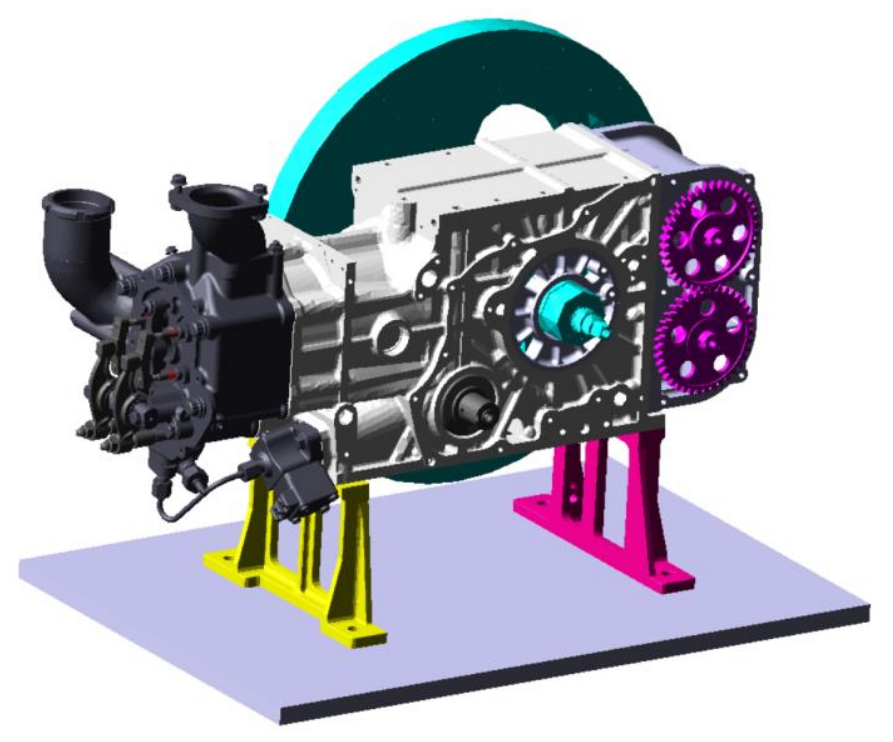

Figure 6. Complete engine model of the DK32 single-cylinder engine.

Table 1. Component mass and simulation model information of the DK32 engine.

\begin{tabular}{|c|c|c|c|}
\hline Component & Mass (kg) & Moment of Inertia $\left(\mathrm{kg}-\mathrm{mm}^{2}\right)\left(\mathrm{I}_{\mathrm{xx}}, \mathrm{I}_{\mathrm{yy}}, \mathrm{I}_{\mathrm{zz}}\right)$ & Simulation Model \\
\hline Engine body & 41.060 & $1.768 \times 10^{6}, 4.950 \times 10^{6}, 1.566 \times 10^{6}$ & Flexible body \\
\hline Crankshaft & 37.959 & $1.124 \times 10^{6}, 9.673 \times 10^{5}, 9.800 \times 10^{5}$ & Flexible body \\
\hline Piston set & 2.712 & $3.587 \times 10^{3}, 3.252 \times 10^{3}, 3.162 \times 10^{3}$ & Rigid body \\
\hline Connecting rod & 2.433 & $1.667 \times 10^{4}, 1.567 \times 10^{4}, 1.589 \times 10^{3}$ & Rigid body \\
\hline Front support & 2.832 & $3.775 \times 10^{5}, 2.027 \times 10^{5}, 2.064 \times 10^{5}$ & Flexible body \\
\hline Rear support & 2.843 & $2.329 \times 10^{5}, 2.058 \times 10^{5}, 5.578 \times 10^{4}$ & Flexible body \\
\hline First-order balance weight & 4.868 & $2.006 \times 10^{4}, 1.882 \times 10^{4}, 7.634 \times 10^{3}$ & Rigid body \\
\hline $\begin{array}{l}\text { Second-order balance weight } \\
\text { (based on conventional method) }\end{array}$ & 0.971 & $1.839 \times 10^{3}, 1.836 \times 10^{3}, 7.682 \times 10^{1}$ & Rigid body \\
\hline $\begin{array}{l}\text { Second-order balance weight } \\
\text { (based on closed-form method) }\end{array}$ & 1.000 & $1.896 \times 10^{3}, 1.893 \times 10^{3}, 7.920 \times 10^{1}$ & Rigid body \\
\hline
\end{tabular}

Table 2. Constrain relationship between components of the DK32 engine model.

\begin{tabular}{ccc}
\hline Component 1 & Component $\mathbf{2}$ & Constrain Relationship \\
\hline Crankshaft & Connecting rod & Revolute \\
Crankshaft & Engine body & Revolute \\
Piston set & Connecting rod & Revolute \\
Piston set & Engine body & Translational \\
First-order balance weight & Engine body & Revolute \\
Second-order balance weight & Engine body & Revolute \\
Engine body & Front support & Fixed \\
Engine body & Rear support & Fixed \\
Front support & Plate & Fixed \\
Rear support & Plate & Fixed \\
Plate & Ground & Fixed \\
\hline
\end{tabular}

To verify the vibration reduction effect, we select six test points on the engine body, the location of which are shown in Figure 7. Using dynamic simulation, we compared the first-order balance mechanism with the novel coaxial balance mechanism based on the closed-form method under four different crankshaft speeds (800, 1500, 1800, and $2350 \mathrm{r} / \mathrm{min}$ ) and one based on the novel closed-form method. Additionally, the average root mean square velocity (denoted as the velocity (RMS)) of the six test points in the direction of piston motion ( $Y$ direction) was compared under two cases in which the coaxial balance mechanism based on the novel closed-form method was installed or the coaxial 
balance mechanism using the second-order balance mass of the conventional design was installed. When the velocity (RMS) was smaller in this direction, the vibration reduction effect was improved.

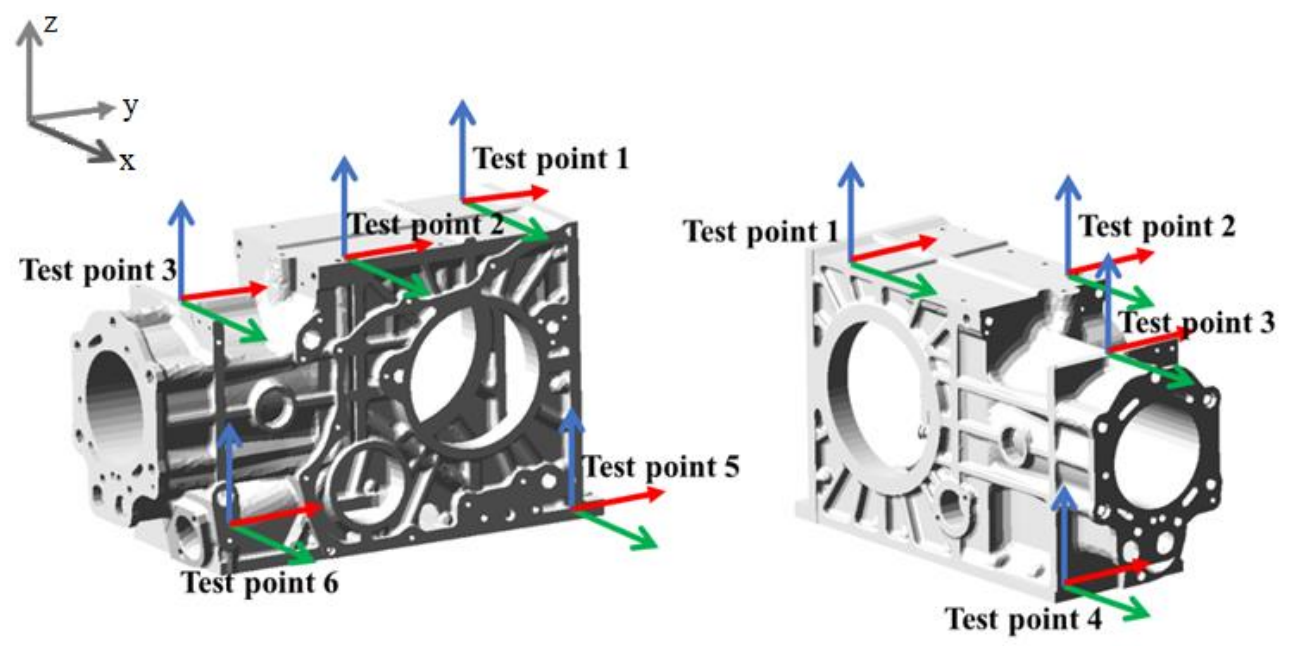

Figure 7. Test point positions on the engine body.

The experimental frequency and computational frequency of the whole engine model were compared as shown in Table 3, in which the root mean square error is less than $4.6 \%$. Thus, the simulation results had good agreement with the experimental data.

Table 3. Comparison of experimental frequency and computational frequency.

\begin{tabular}{cccc}
\hline \multirow{2}{*}{ Order } & \multicolumn{3}{c}{ Frequency $(\mathrm{Hz})$} \\
\cline { 2 - 4 } & Experiment & Computation & Error \\
\hline No. 1 & 23.75 & 23.45 & $1.26 \%$ \\
No. 2 & 30.88 & 30.68 & $0.65 \%$ \\
No. 3 & 51.99 & 49.89 & $4.04 \%$ \\
No. 4 & 61.05 & 62.24 & $1.95 \%$ \\
No. 5 & 74.71 & 68.87 & $7.82 \%$ \\
No. 6 & 87.3 & 81.55 & $6.59 \%$ \\
\hline
\end{tabular}

To validate the simulation model, we carried out a vibration experiment of the DK32 single-cylinder engine, as shown in Figure 8. The acceleration time-domain curves in the direction of piston motion ( $Y$ direction) of test point 6 at speeds 800 and $1500 \mathrm{r} / \mathrm{min}$ are shown in Figures 9 and 10, respectively. These figures show that the simulation results were highly consistent with the experimental results. At the speed of $800 \mathrm{r} / \mathrm{min}$, the average root mean square acceleration of experiment and simulation at test point 6 were 0.84 and $0.88 \mathrm{~g}$, respectively. At the speed of $1500 \mathrm{r} / \mathrm{min}$, the average root mean square acceleration of the experiment and simulation at test point 6 were 1.1 and $0.97 \mathrm{~g}$, respectively. The computation model and method proposed in this article were thus verified.

\subsection{Vibration Reduction Effect of the Novel Coaxial Balance Mechanism}

The duration of the simulation was $2 \mathrm{~s}$, and the number of steps was 20,000. The integrator was GSTIFF. The vibration reduction effects from the installations of a first-order balance mechanism and a novel coaxial balance mechanisms based on the closed-form method were then compared. Figure 11 shows the average velocity (RMS) in the direction of piston motion ( $Y$ direction) of six test points under four different crankshaft speeds. 


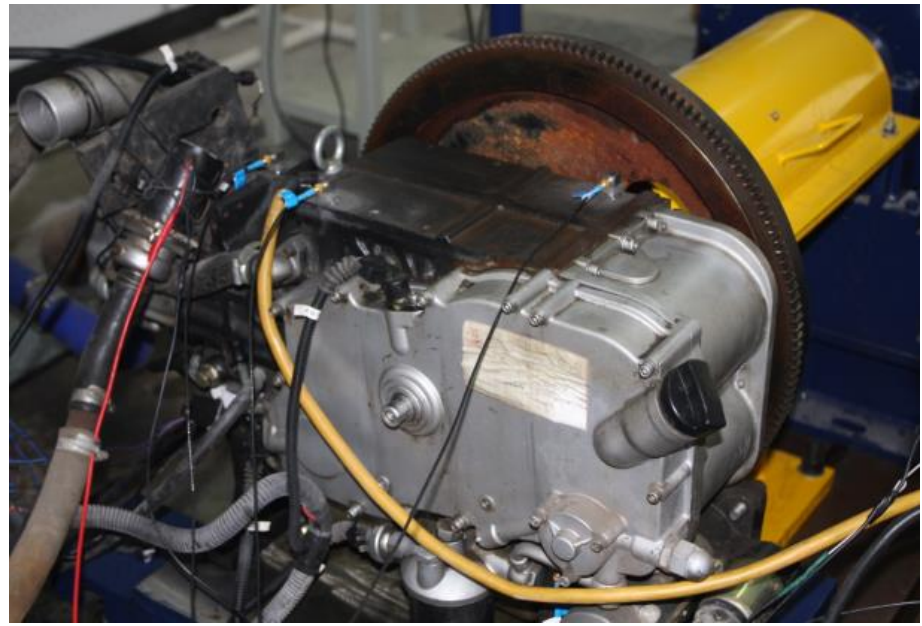

Figure 8. Experimental DK32 single-cylinder engine.

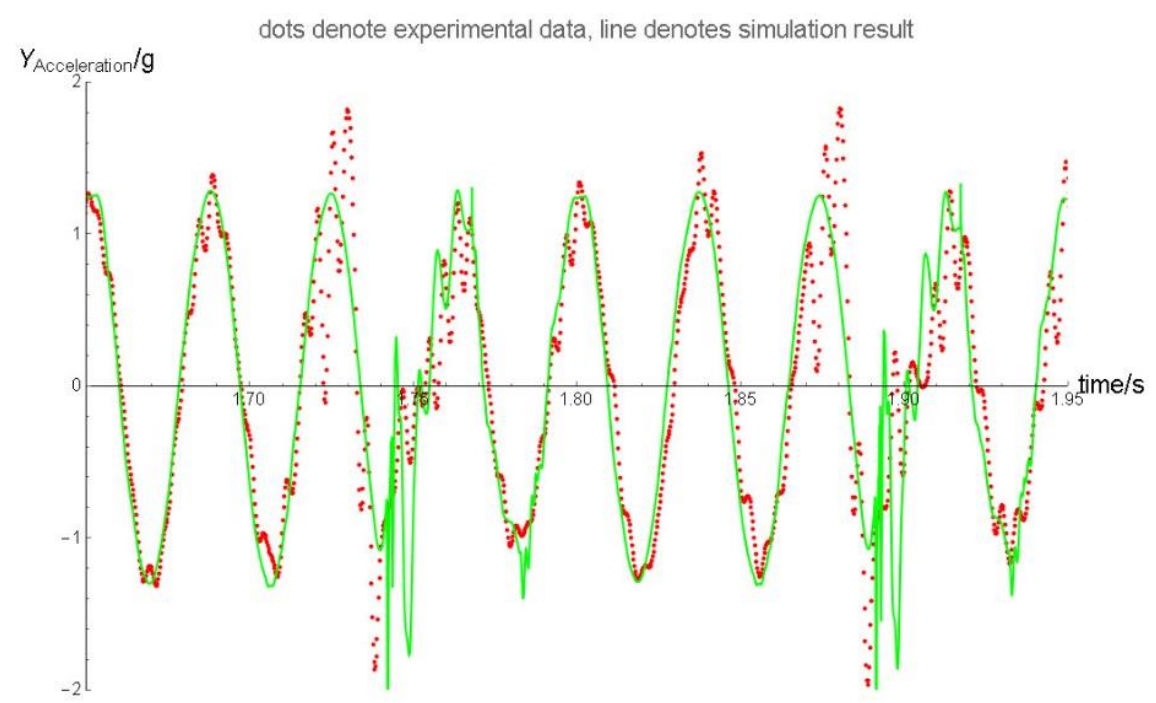

Figure 9. Acceleration time-domain curve in the direction of piston motion (Y direction) of test point 6 at a crankshaft speed of $800 \mathrm{r} / \mathrm{min}$.

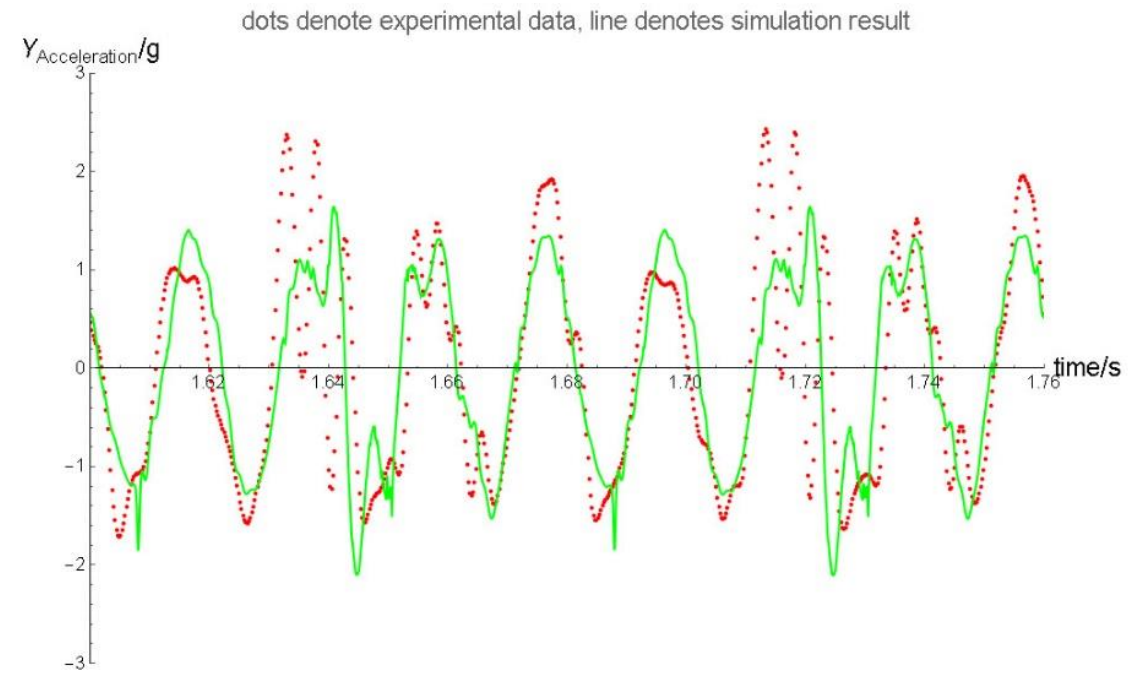

Figure 10. Acceleration time-domain curve in the direction of piston motion (Y direction) of test point 6 at a crankshaft speed of $1500 \mathrm{r} / \mathrm{min}$. 


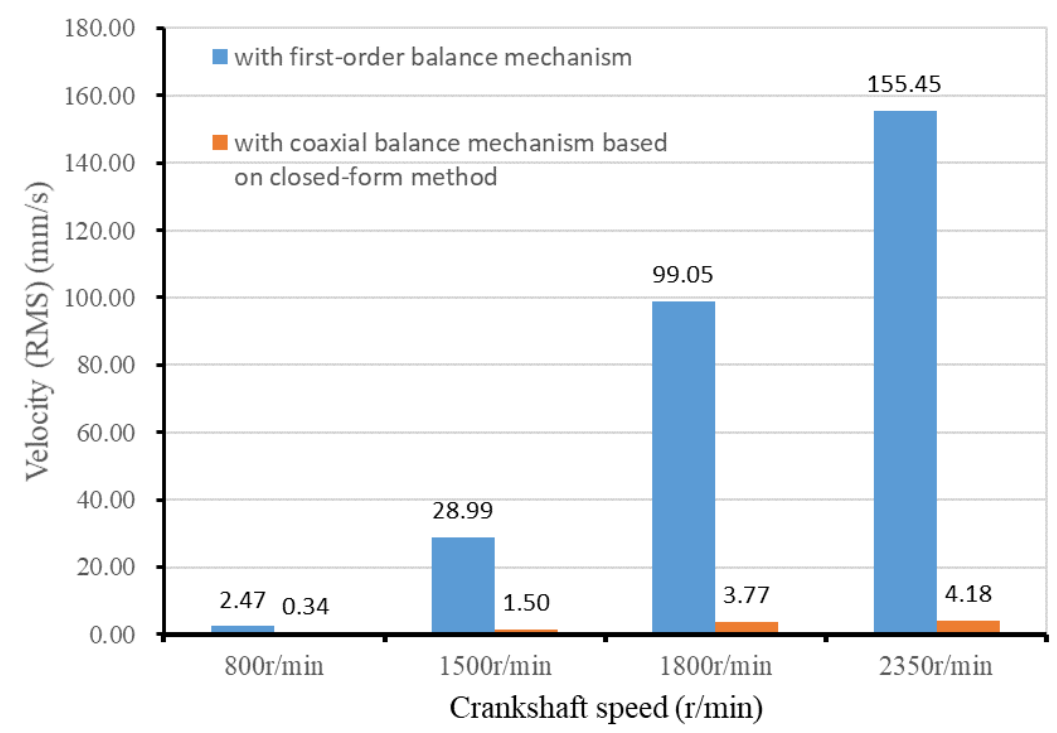

Figure 11. The average velocity (RMS) in the direction of piston motion of the six test points from the installations of a first-order balance mechanism and a novel coaxial balance mechanism based on the closed-form method.

According to Figure 11, compared with a conventional first-order balance device, the average velocity (RMS) of the six test points on the cylinder of the single-cylinder engine with the novel coaxial balance mechanism was significantly reduced. At 800, 1500, 1800, and $2350 \mathrm{r} / \mathrm{min}$, the percentage decrease in the average velocity (RMS) in the direction of piston motion reached $86.25 \%, 94.81 \%, 96.19 \%$, and $97.31 \%$, respectively.

The support reaction force between the plate and the ground, which is another important indicator of the vibration reduction effect, was also calculated when the singlecylinder engine was operating. The results show that, when the support reaction force was smaller, the vibration reduction effect was better. Figure 12 indicates the support reaction force from the installations of a conventional first-order balance mechanism and a novel coaxial balance mechanism under different crankshaft speeds. At 800, 1500, 1800, and $2350 \mathrm{r} / \mathrm{min}$, compared with the first-order balance mechanism, the support reaction force of the novel coaxial balance mechanism was reduced by $90.62 \%, 94.98 \%, 96.12 \%$, and $96.54 \%$, respectively.

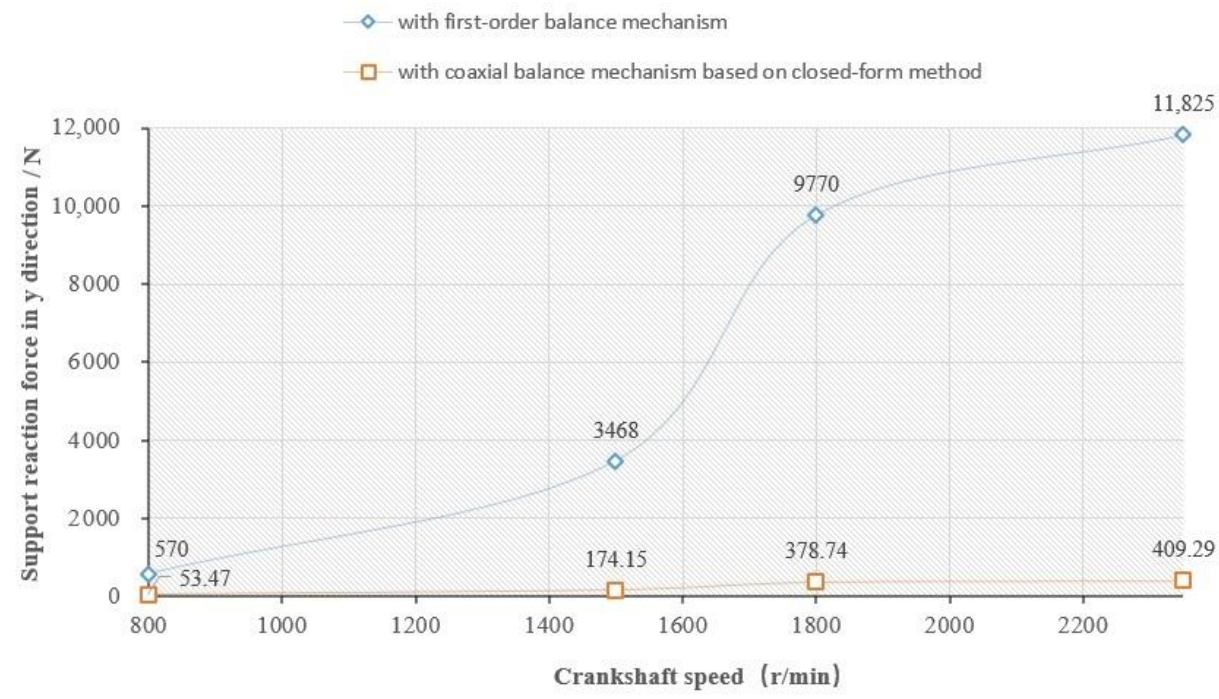

Figure 12. Support reaction force in the direction of piston motion from the installations of a first-order balance mechanism and a novel coaxial balance mechanism based on the closed-form method. 
At a crankshaft speed of $2350 \mathrm{r} / \mathrm{min}$, according to Figures 11 and 12, with the first-balance mechanism installed, the average velocity (RMS) of the six test points on the cylinder of the single-cylinder engine was $155.45 \mathrm{~mm} / \mathrm{s}$ and the support reaction force amplitude was $11,825 \mathrm{~N}$. With the novel coaxial balance mechanism installed, the average velocity (RMS) was reduced to $4.18 \mathrm{~mm} / \mathrm{s}$ and the support reaction force amplitude was reduced to 409 N. Figure 13 shows the time-domain curve of the support reaction force in the direction of piston motion at a crankshaft speed of $2350 \mathrm{r} / \mathrm{min}$.

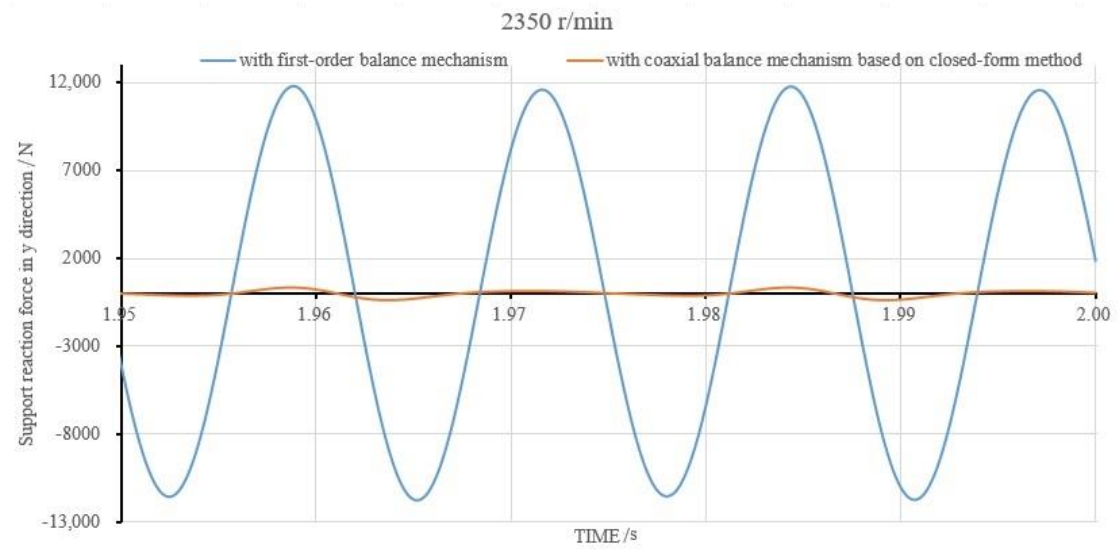

Figure 13. Time-domain curve of support reaction force in the direction of piston motion at a crankshaft speed of $2350 \mathrm{r} / \mathrm{min}$.

\subsection{Comparison of Vibration Reductions Using the Closed-Form Method and the Conventional Method}

Next, we compared the average velocity (RMS) of the relevant test points in a single-cylinder engine, and the support reaction force in the piston motion direction from installations of the novel coaxial balance mechanism based on the closed-form method, and the coaxial balance mechanism with a conventional second-order balance mass and different crankshaft speeds.

According to Figures 14 and 15, compared with the coaxial balance mechanism based on the conventional second-order method, the average velocity (RMS) of the six test points of the cylinder of the single-cylinder engine and the support reaction force with the novel coaxial balance mechanism with the closed-form method was reduced. At 800, 1500, 1800, and $2350 \mathrm{r} / \mathrm{min}$, the percentage decrease in the average velocity (RMS) in the direction of piston motion was $5.75 \%, 28.68 \%, 41.12 \%$, and $47.53 \%$, respectively, and the support reaction force was reduced by $22.45 \%, 35.26 \%, 39.73 \%$, and $42.69 \%$, respectively.

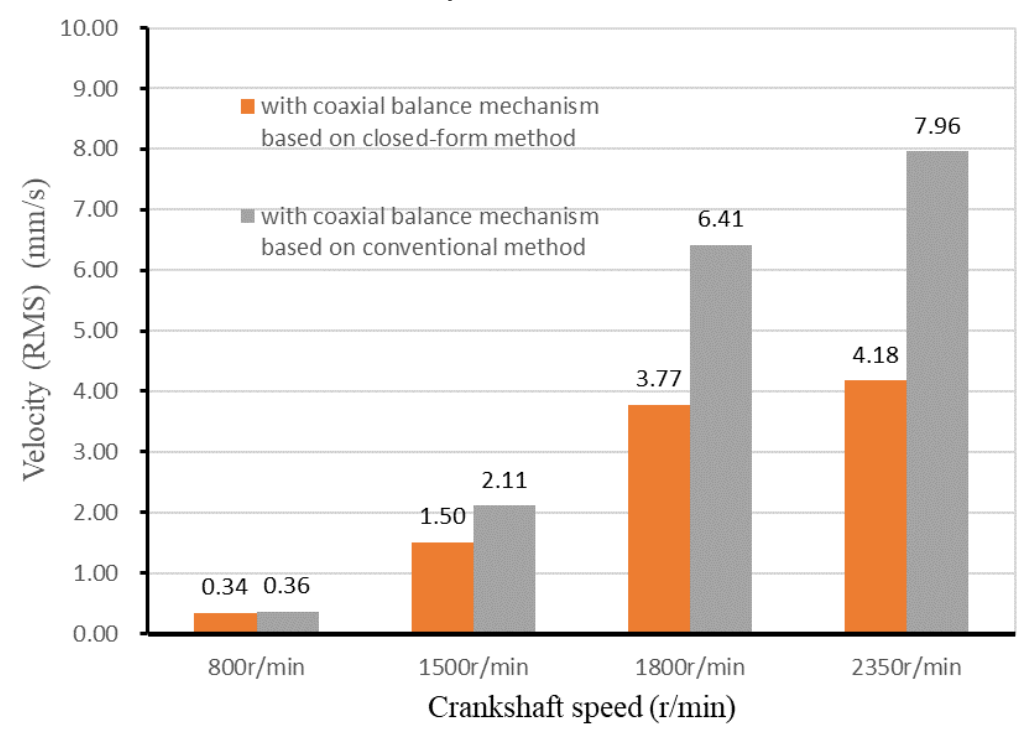

Figure 14. The average velocity (RMS) in the direction of the piston motion of the six test points with the novel coaxial balance mechanism based on the closed-form method and a conventional method, respectively. 


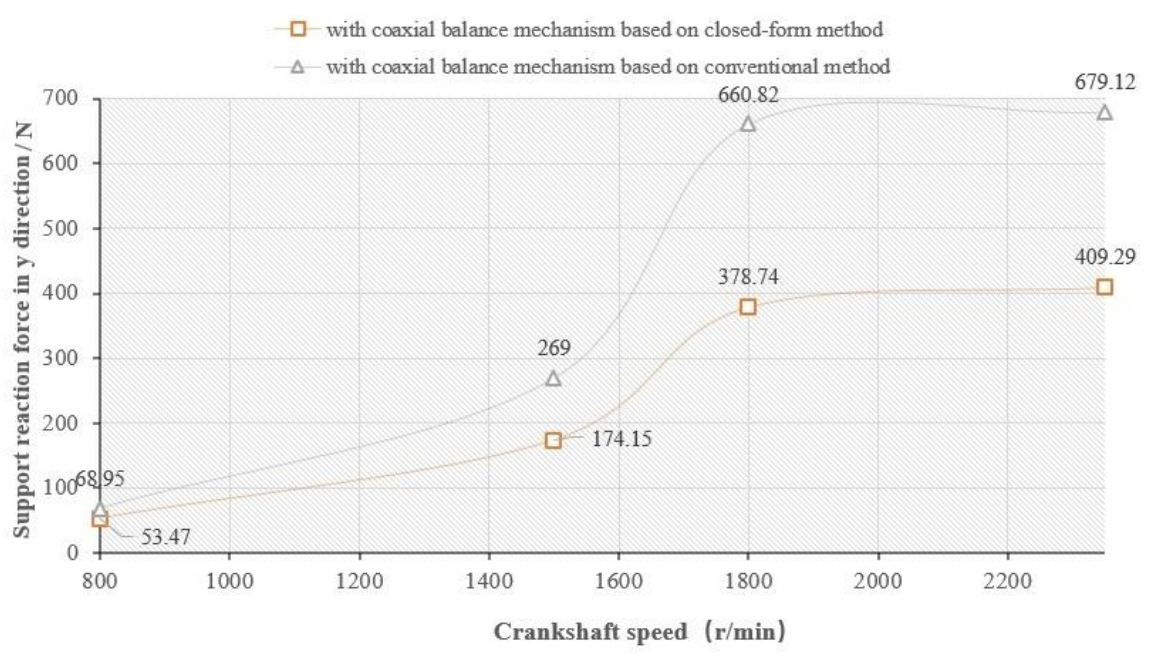

Figure 15. Support reaction force in the direction of piston motion in the two cases with the novel coaxial balance mechanism based on the closed-form method and conventional method, respectively.

\section{Conclusions}

To reduce the vibration of piston engines without increasing the engine body size or requiring additional design features, this work proposed a high-order coaxial balancing mechanism solution. In this proposed design, the second-order balance mass block is arranged inside the original first-order balance mass block, and the two balance mass blocks undergo coaxial rotation at different speeds.

The novel mechanism was applied to a DK32 single-cylinder engine developed in a laboratory setting as an example. Dynamics simulations of the whole engine using Adams software were carried out in detail. Compared with the first-order balance device, the test point velocity on the cylinder of the single-cylinder engine with the novel coaxial balance mechanism was significantly reduced. The simulation results showed that at $800,1500,1800$, and $2350 \mathrm{r} / \mathrm{min}$, the percentage decrease in the average velocity (RMS) in the direction of piston motion was $86.25 \%, 94.81 \%, 96.19 \%$, and $97.31 \%$, respectively. The support reaction force decreased by $90.62 \%, 94.98 \%, 96.12 \%$, and $96.54 \%$ at 800,1500 , 1800 , and $2350 \mathrm{r} / \mathrm{min}$, respectively. A crankshaft speed of $2350 \mathrm{r} / \mathrm{min}$ was taken as an example, and with the first-balance mechanism installed, the average velocity (RMS) of the six test points on the cylinder of the single-cylinder engine was $155.45 \mathrm{~mm} / \mathrm{s}$ and the support reaction force amplitude was $11,825 \mathrm{~N}$. In comparison, with the novel coaxial balance mechanism installed, the average velocity (RMS) was reduced to $4.18 \mathrm{~mm} / \mathrm{s}$ and the support reaction force amplitude was reduced to $409 \mathrm{~N}$.

To summarize, the novel coaxial balance mechanism plays a significant role in vibration reductions. Based on this design concept and, by analogy, the fourth-order balance mechanism could be realized by adding a planetary gear transmission mechanism with a hole inside the second-order balance shaft to balance the fourth-order inertia force. The design retains the original unit body module and does not increase the dimensions of the mechanism.

The novel closed-form method used in this study can improve the accuracy of calculating second-order balance mass. By comparing the support reaction force in dynamics simulations, at $800,1500,1800$, and $2350 \mathrm{r} / \mathrm{min}$, the percentage decrease in the average velocity (RMS) in the direction of piston motion reached $5.75 \%, 28.68 \%, 41.12 \%$, and $47.53 \%$, respectively. Additionally, the support reaction force was reduced by $22.45 \%, 35.26 \%$, $39.73 \%$, and $42.69 \%$, respectively. Using the novel closed-form method, we further enhanced the vibration reduction effect of the coaxial balance mechanism. By adopting a compact unit-body design, the workload and cost of modification could be reduced for all types of single-cylinder or multiple-cylinder engines in service, and the goal of reducing the vibration of the original model could be achieved by adding second- and higher-order 
balance mechanisms without changing the existing balance mechanism configuration or increasing the dimensions.

Future research should expand the scope of the novel coaxial balance mechanism. This mechanism is independent of the engine configuration, and can thus be conveniently used for various engine configurations to balance higher-order inertia loading, including eccentric and single- or multi-cylinder engines, or other mechanisms with a connecting rod and crank.

Author Contributions: Conceptualization, N.G., Z.X. and M.Z.; methodology, N.G. and Z.X.; software, N.G., Z.X., A.W. and Y.G.; validation, N.G. and Z.X.; formal analysis, N.G.; investigation, N.G., Z.X. and Y.G.; resources, M.Z.; data curation, N.G. and Z.X.; writing-original draft preparation, N.G. and Z.X.; writing-review and editing, N.G., Z.X., Y.G. and M.Z.; visualization, N.G., A.W., Z.X. and Y.G.; supervision, M.Z.; project administration, M.Z. All authors have read and agreed to the published version of the manuscript.

Funding: This research received no external funding.

Institutional Review Board Statement: Not applicable.

Informed Consent Statement: Not applicable.

Data Availability Statement: The data presented in this study are available on request from the corresponding author.

Conflicts of Interest: The authors declare no conflict of interest.

\section{References}

1. Xin, Q. Diesel Engine System Design; Elsevier: Amsterdam, The Netherlands, 2011.

2. Zouani, A.; Hanim, S. Overview of noise and vibration in automotive engines. Int. J. Veh. Noise Vib. 2016, 12, 162-181. [CrossRef]

3. Carlucci, A.P.; Chiara, F.F.; Laforgia, D. Analysis of the relation between injection parameter variation and block vibration of an internal combustion diesel engine. J. Sound Vib. 2006, 295, 141-164. [CrossRef]

4. Griffiths, W.J.; Skorecki, J. Some aspects of vibration of a single cylinder diesel engine: A. Effects of cooling water on cylinder pressure and surface vibration B. Mechanics of piston slap. J. Sound Vib. 1964, 1, 345. [CrossRef]

5. Fabi, P.; Flekiewicz, M.; Madej, H.; Wojnar, G.; Flekiewicz, B. Influence of Piston Slap on Engine Block Vibration; SAE Technical Paper 2007-01-2163; SAE International: Warrendale, PA, USA, 2007. [CrossRef]

6. Wang, C.; Zhang, Y.; Zhong, Z. Fault diagnosis for diesel valve trains based on time-frequency images. Mech. Syst. Signal Process. 2008, 22, 1981-1993. [CrossRef]

7. Singh, O.P.; Sreenivasulu, T.; Kannan, M. The effect of rubber dampers on engine's NVH and thermal performance. Appl. Acoust. 2014, 75, 17-26. [CrossRef]

8. Ågren, A.; Johansson, Ö.; Klopotek, M. Noise reduction of diesel engines with internal stiffeners. Noise Control Eng. J. 1997, 45, 1-13. [CrossRef]

9. Shangguan, W.-B. Engine mounts and powertrain mounting systems: A review. Int. J. Veh. Des. 2009, 49, 237-258. [CrossRef]

10. Li, S.Y.; Yuan, Z.C.; Ma, J.Y.; Liu, M.; Yu, Y.X. Balance and Vibration analysis on an in-line five cylinders engine. Adv. Mater. Res. 2013, 694, 297-301. [CrossRef]

11. Aversa, R.; Petrescu, R.V.; Akash, B.; Bucinell, R.; Corchado, J.; Chen, G.; Li, S.; Apicella, A.; Petrescu, F.I. Something about the balancing of thermal motors. Am. J. Eng. Appl. Sci. 2017, 10, 200-217. [CrossRef]

12. Razzini, J.; Vandresen, M. Three Cylinder Engine Balancing Model; SAE Technical Paper 2020-36-0097; SAE International: Warrendale, PA, USA, 2021. [CrossRef]

13. Mahdisoozani, H.; Mohsenizadeh, M.; Bahiraei, M.; Kasaeian, A.; Daneshvar, A.; Goodarzi, M.; Safaei, M.R. Performance Enhancement of Internal Combustion Engines through Vibration Control: State of the Art and Challenges. Appl. Sci. 2019, 9, 406. [CrossRef]

14. Ricardo, H.R. Frederick William Lanchester, 1868-1946; Royal Society: London, UK, 1948.

15. Sun, S.; Zhang, Y.; Wei, S. Trend of Balance Design of Four-Cylinder Diesel Engine. Des. Manuf. Diesel Engine 2002, 4, 4-9. (In Chinese)

16. Koji, O.; Shinsuk, M.; Akira, M. Development of diesel engines for small trucks and buses. Light Veh. Technol. 1999, 6, 28-32.

17. Huegen, S.; Warren, G.; Menn, R. A New 2.3 L DOHC Engine with Balance Shaft Hous-ing-Steps of Refinement and Optimization. Soc. Automot. Eng. 1997, 970921, 153-161.

18. Adachi, S.; Horio, K.; Nakamura, Y. Development of Toyota 1ZZ-FE Engine; International Congress and Exposition: Detroit, MI, USA, 1998.

19. Zhang, H. Research on Engine Balancing Scheme and Software Development. Master's Thesis, Zhongbei University, Taiyuan, China, 2016. (In Chinese). 
20. Qiu, J.; Pan, C.; Mu, X.; Zhou, M. Design and Simulation of an Electronically Controlled Single-Cylinder Diesel Engine to Lower Emissions. J. Energy Eng. 2017, 143, 04017024. [CrossRef]

21. Zhang, K.; Huang, X.; Xie, Z.; Zhou, M. Design and optimization of a novel electrically controlled high pressure fuel injection system for heavy fuel aircraft piston engine. Chin. J. Aeronaut. 2018, 31, 1920-1928. [CrossRef]

22. Heisler, H. Advanced Engine Technology; Society of Automotive Engineers: Warrendale, PA, USA, 1995.

23. Mollenhauer, K.; Tschöke, H. Handbook of Diesel Engines; Springer: Berlin, Germany, 2010.

24. Xie, Z.; Xu, Q.; Guan, N.; Zhou, M. A new closed-form method for inertia force and moment calculation in reciprocating piston engine design. Sci. China Technol. Sci. 2018, 61, 879-885. [CrossRef]

25. Xie, Z.; Xu, Q.; Guan, N.; Xia, A.; Zhou, Y.; Tu, H.; Zhou, S.; Lan, X.; Zhou, M.; Huang, X.; et al. Balance Mechanism. China Patent ZL 201611100630, 22 September 2017.

26. Karabulut, H.; Ipci, D. Torsional vibration moment analysis of a three-cylinder internal combustion engine. Int. J. Veh. Noise Vib. 2018, 14, 147-170. [CrossRef]

27. Drab, C.B.; Engl, H.W.; Haslinger, J.R.; Offner, G.; Pfau, R.U.; Zulehner, W. Dynamic simulation of crankshaft multibody systems. Multibody Syst. Dyn. 2009, 22, 133-144. [CrossRef]

28. Stout J, L. Concept level powertrain radiated noise analysis. SAE Trans. 1999, 108, 2776-2781.

29. Wagg, D.J.; Worden, K.; Barthorpe, R.J.; Gardner, P. Digital Twins: State-of-the-Art and Future Directions for Modeling and Simulation in Engineering Dynamics Applications. ASCE-ASME J. Risk Uncertain. Eng. Syst. Part B Mech. Eng. 2020, 6, 030901. [CrossRef]

30. Ma, Z.-D.; Perkins, N.C. An efficient multibody dynamics model for internal combustion engine systems. Multibody Syst. Dyn. 2003, 10, 363-391. [CrossRef] 